\title{
DETERMINANTES DO SPREAD BANCÁRIO NO BRASIL E OS EFEITOS DO ACORDO DE BASILEIA III
}

\author{
Felipe de Oliviera Cavalcanti * \\ Carlos Enrique Carrasco Gutierrez ${ }^{\dagger}$ \\ Jéssica Filardi Milker Figueiredo ${ }^{\ddagger}$
}

\begin{abstract}
Resumo
Este artigo estuda os determinantes do spread bancário ex-post na economia brasileira, em particular, buscamos evidências dos efeitos da implementação do acordo de Basileia III no spread. Baseados no modelo teórico apresentado por Ho \& Saunders (1981), estimamos um modelo dinâmico para dados em painel para 73 bancos comerciais em operação no Brasil correspondentes ao período 2009:2 e 2016:2. Os resultados apontam evidências das novas exigências de capital de nível 1 e capital principal que afetam de forma positiva o spread bancário. Outras variáveis que foram identificadas como determinantes do spread são: despesas administrativas e operacionais, tributação, lucro líquido dos bancos, desemprego e taxa Selic.
\end{abstract}

Palavras-chave: spread, Basileia III, crédito, bancos.

Códigos JEL: E51, G10, G21.

\begin{abstract}
This article studies the determinants of Brazilian ex-post bank spread, in particular, we seek evidence of the Basel III agreement implementation effects on Brazilian spread. Based on a model presented by Ho \& Saunders (1981), we estimated a panel model with data of 73 commercial banks operating in Brazil from 2009:2 to 2016:2. The results showed evidence of a positive impact on ex-post bank spread of the new capital requirements of the Basel III agreement in Brazil. Other variables that have been identified as determinants of the spread are: administrative expenses, taxation, banks' net profit, unemployment and the Selic rate.
\end{abstract}

Keywords: spread, Basel III, credit, banks.

JEL codes: E51, G10, G21.

DOI: http://dx.doi.org/10.11606/1980-5330/ea173229

\footnotetext{
* Universidade Católica de Brasília, Programa de Pós-Graduação em Economia, SGAN 916, Módulo B. Brasília CEP 70790-160, DF - Brasil. E-mail: ffeliped@bb.com.br.

† Universidade Católica de Brasília, Programa de Pós-Graduação em Economia, SGAN 916, Módulo B. Brasília CEP 70790-160, DF - Brasil. E-mail: carlos .carrasco.gutierrez@gmail.com.

‡ Universidade Católica de Brasília, Programa de Pós-Graduação em Economia, SGAN 916, Módulo B. Brasília CEP 70790-160, DF - Brasil. E-mail: jessica_milker@hotmail.com.br.
} 


\section{Introdução}

O spread bancário é a diferença entre as taxas de juros cobradas nos empréstimos ou financiamentos efetuados pelos bancos e as taxas de juros pagas por eles em sua atividade de captação. Trata-se, portanto, de um importante indicador da eficiência do sistema financeiro, pois representa o custo da atividade de intermediação financeira entre os agentes superavitários e os agentes deficitários de uma economia. Se esse custo for demasiadamente elevado, as taxas de crédito podem se situar em patamares que dificultam o financiamento de projetos estruturantes em diversos setores, além de inibir o consumo, principalmente, de bens duráveis, gerando impactos diretos sobre o crescimento econômico.

Para aumentar o bem-estar social, é necessário reduzir esse custo de intermediação, e, para isso, é preciso conhecer os fatores que explicam esse spread. Além disso, é sabido que exigências regulatórias e prudenciais podem ser consideradas pelos bancos no momento da definição do spread bancário. Alguns desses impactos foram detectados por autores como Angbazo (1997) e Valverde \& Fernández (2007). Nesse sentido, é preciso conhecer os principais determinantes do spread bancário no Brasil, pois, uma vez que se pontua seus motivadores, é possível adotar medidas mais eficientes para promover sua redução. O maior controle sobre essa variável financeira deve, também, viabilizar um novo mecanismo de estímulo econômico ao consumo e ao investimento do país.

No entanto, como mencionado anteriormente, a gestão financeira dos bancos e, naturalmente, a escolha das taxas de juros cobradas e pagas por essas instituições no desenvolvimento de sua atividade estão sujeitas a normas nacionais e internacionais de boas práticas. Esse conjunto de regras está em contínuo processo de aperfeiçoamento e de mudanças das exigências de forma que a sua implementação nos mercados tende a gerar impactos sobre as decisões bancárias. Em vista disso, avaliar como modificações normativas interferem no spread é importante para entender essa dinâmica e, a partir disso, poder elaborar políticas voltadas a sua redução e, consequentemente, ao estímulo à atividade econômica.

Em nível internacional, os níveis prudenciais da estrutura de capital dos bancos são recomendados pelo Acordo de Basileia III, incorporados ao ordenamento normativo brasileiro pelo Conselho Monetário Nacional (CMN) e pelo BCB - Banco Central do Brasil (2013). Nessa perspectiva, faz-se oportuno avaliar como e em qual intensidade a sua implementação impactou o spread brasileiro.

Este trabalho tem como objetivo estudar os determinantes do spread bancário ex-post na economia brasileira, em particular, estamos interessados em verificar se a implementação do acordo de Basileia III teve algum efeito no spread. Partindo do modelo teórico apresentado por Ho \& Saunders (1981) e um modelo dinâmico para dados em painel, procedemos com a abordagem empírica, usando variáveis que representam a concentração de mercado, as características particulares dos bancos e alguns indicadores macroeconômicos, para uma amostra de 73 bancos comerciais em operação no Brasil correspondentes ao período trimestral entre 2009:2 e 2016:2.

Os resultados evidenciam relações positivas e significantes do spread com as despesas administrativas e operacionais, a tributação, o lucro líquido dos bancos e o desemprego, além de uma associação estatisticamente significante 
e negativa com a taxa Selic, corroborando os resultados achados em Almeida \& Divino (2015), Oreiro et al. (2006) e Afanasieff et al. (2002). Também observaram-se evidências de que as exigências de capital de nível 1 e de capital principal, majoradas com a implementação do Acordo de Basileia III no Brasil, têm um efeito positivo no spread.

Este trabalho traz contribuições para a literatura no estudo do efeito da implementação do Acordo de Basileia III no spread bancário brasileiro, não tratado em outros trabalhos. Evidencia-se nele que a avaliação do impacto das limitações à capacidade de alavancagem das instituições financeiras impostas pelo novo conjunto de regras internacionais sobre o spread bancário brasileiro colabora para o arcabouço instrumental das autoridades monetárias do país disponível para o estímulo à economia nacional.

Além desta introdução, este artigo é composto por 5 partes: a segunda seção apresenta uma breve revisão da teoria existente sobre os determinantes do spread bancário e sobre o Acordo de Basileia III. A terceira e a quarta seções apresentam a metodologia empregada na pesquisa e os dados utilizados, respectivamente. Os resultados serão apresentados na quinta seção e, por fim, a conclusão na última seção.

\section{Literatura Sobre o Spread Bancário}

A partir de seu trabalho seminal, Ho \& Saunders (1981), utilizando uma série de dados trimestrais com base nas informações contábeis dos maiores bancos dos Estados Unidos, entre os anos de 1976 e 1979, argumentam que a volatilidade da taxa de juros cobrada sobre os empréstimos realizados no mercado bancário pode ser reflexo direto da estabilidade macroeconômica do país.

Angbazo (1997) modificou o modelo proposto por Ho \& Saunders (1981) a partir da inclusão do risco de crédito e sua interação com o risco de taxas de juros no "puro spread". Com uma amostra com 1400 observações, referentes a 286 bancos americanos entre os anos de 1989 e 1993, o autor efetuou uma análise empírica, regredindo as margens líquidas dos bancos contra as mesmas variáveis consideradas no artigo original e acrescentou alguns fatores específicos dos bancos. Dessa forma, encontrou uma relação positiva entre a margem líquida e os seguintes fatores: risco de crédito, risco de taxas de juros, exigência de capital, custo de oportunidade das reservas e a falta de qualidade da administração. Observou, ainda, uma relação negativa com o risco de liquidez.

Saunders \& Schumacher (2000) estudaram os determinantes do spread usando como amostra informações referentes ao período de 1988 a 1995 dos bancos de 7 países da OECD: Alemanha, Espanha, França, Grã-Bretanha, Itália, Estados Unidos e Suíça. Tendo por base o modelo de Ho \& Saunders (1981), os autores investigaram a influência de três componentes nas margens dos bancos, quais sejam: (i) impostos ou reservas requeridas; (ii) a estrutura de mercado que reflete o nível de monopólio da economia; (iii) um componente de risco, refletindo o risco assumido pelos bancos, especialmente aquele associado às oscilações nas taxas de juros da economia.

Kunt e Huizinga (1998) realizaram uma pesquisa bastante abrangente. Com uma base de dados com informações contábeis de 7.900 bancos de 80 países, entre os anos de 1988 e 1995, esses autores efetuaram a decomposição do spread bancário e analisaram os seus determinantes do ponto de vista econô- 
mico. Fazendo uma avaliação ex-post e comparando os resultados entre os bancos dos diversos países, concluíram que existem diferenças significativas em relação às características dos bancos e seus macroambientes (regulação, taxação explícita e implícita, seguro dos depósitos, inflação, taxa de juros da economia, etc.) que afetam diretamente o tamanho de suas margens. Essa pesquisa mostrou também que o spread praticado no Brasil estava entre os maiores do mundo. A análise empírica encontrou uma relação positiva entre o nível de capitalização e a rentabilidade, e negativa entre as reservas e a rentabilidade dos bancos. Mostrou ainda que incertezas relacionadas com o desenvolvimento e a estabilidade do país impactam positivamente o spread e que os custos referentes aos impostos corporativos incidentes sobre a intermediação financeira são repassados para o consumidor final.

Maudos \& Guevara (2004) realizaram um estudo empírico utilizando como amostra dados anuais de 1.826 bancos da Alemanha, França, Reino Unido, Itália e Espanha, entre os anos de 1993 e 2000. O modelo implementado é similar ao proposto por Ho \& Saunders (1981) e suas extensões, porém, com a inclusão de uma variável para representar os custos explícitos. Trabalhando com dados em painel, por meio de uma regressão em apenas um estágio, os autores chegaram a estimadores significantes para todas as variáveis propostas, a saber: estrutura de mercado (utilizando com proxies o índice de Lerner e o índice de Herfindahl), custos operacionais unitários, grau de aversão ao risco, volatilidade da taxa de juros do mercado, risco de crédito, covariância entre risco de taxa de juros e risco de crédito, tamanho médio das operações, volume de crédito concedido, pagamento de juros implícitos, custos de oportunidade sobre as reservas e a qualidade da administração. Dentre as variáveis que mais afetaram o spread positivamente (aumentaram o spread), destacaram-se a estrutura dos mercados e os custos explícitos, enquanto a que mais reduziu o spread foi a qualidade da administração (mesurada por meio da razão custos/receita).

Valverde \& Fernández (2007) avaliaram uma amostra com 19.332 bancos europeus de Alemanha, Espanha, França, Holanda, Itália, Reino Unido e Suécia, no período compreendido entre 1994 e 2001. Aplicando a metodologia proposta por Ho \& Saunders (1981), com uma adaptação para considerar receitas não oriundas dos juros dos empréstimos, como tarifas. Os resultados alcançados mostraram, entre outras coisas, que o nível de especialização dos bancos tinha um coeficiente negativo e significante em relação ao spread. Isso indica que bancos especializados cobram menores spreads. Além disso, os autores encontraram coeficientes positivos e significantes para o risco de crédito, o risco de liquidez, o risco de taxa de juros (mercado), entre outros, e analisaram também as variáveis que explicam o índice de Lerner.

Almarzoqi \& Naceur (2015) estudaram os determinantes do spread na região do Cáucaso e na Ásia Central, utilizando dados em painel de 7 países (Armênia, Azerbaijão, Geórgia, Cazaquistão, Tajiquistão e Uberquistão) e o estimador dinâmico GMM. Os autores regrediram o spread contra variáveis específicas dos bancos, índice de Lerner e fatores macroeconômicos, encontrando resultados positivos e significantes para os custos operacionais, tamanho das operações e custo de oportunidade das reservas para a região. O coeficiente referente às receitas não financeiras foi negativo e significante. Ao contrário de estudos anteriores, o risco de crédito, a estrutura de mercado e o desenvolvimento macroeconômico não foram significantes. Outras conclusões importantes são que a eficiência operacional é o fator mais importante para a 
redução do spread e que a adequação de capital não foi significante.

No Brasil, o elevado nível de spread praticado no país motivou a realização de diversos estudos empíricos para identificação de suas causas e definição de estratégias que conseguissem reduzi-lo. Entre eles, destacam-se alguns realizados por pesquisadores de órgãos públicos como o BCB, o Instituto de Pesquisa Econômica Aplicada (IPEA) e o Senado Federal, além de alguns trabalhos acadêmicos.

Afanasieff et al. (2002) utilizaram uma extensão da metodologia desenvolvida por Ho \& Saunders (1981) para identificar os principais determinantes do spread bancário praticado no Brasil. Com dados mensais de todos os bancos comerciais em operação no Brasil (142 bancos) durante fevereiro de 1997 e novembro de 2000. Foram encontradas relações positivas do spread com a taxa básica de juros, com o prêmio de risco, com o crescimento da produção e com a taxação. O coeficiente em relação ao incremento das reservas foi positivo, embora não significante. Ao contrário das expectativas, a inflação afetou negativamente o spread no período.

Oreiro et al. (2006) procuraram identificar os determinantes do spread dando ênfase aos possíveis impactos de fatores macroeconômicos. Por meio de uma modelo VAR e funções impulso resposta, concluíram que a elevada volatilidade da taxa de juros que aumenta o risco de mercado, o nível da taxa de juros que serve como "custo de oportunidade" para as operações de empréstimos e o nível de produção industrial que pode elevar a demanda, destacam-se como principais determinantes do spread no Brasil.

Também visando identificar os determinantes do spread, Manhiça \& Jorge (2012) elaboraram um modelo econométrico composto por variáveis que caracterizam a estrutura de mercado, variáveis microeconômicas e variáveis macroeconômicas, incluindo a taxa de juros em nível e a variância da taxa de juros. A partir de dados em painel (em um modelo System GMM) com informação para 140 bancos comerciais que operaram no Brasil entre 2000 e 2010, os autores chegaram a resultados ambíguos em relação às variáveis de estrutura de mercado. Diferentemente do apontado no estudo de Oreiro et al. (2006), algumas variáveis microeconômicas foram importantes para explicar o spread, como os custos operacionais, o nível de alavancagem e o desempenho patrimonial. Em relação às variáveis macroeconômicas que também foram o foco principal do estudo, a inflação, o desemprego e as taxas de juros se mostraram significantes a $1 \%$ e positivos. Apenas a volatilidade da taxa de juros não foi capturada pelo spread.

Almeida \& Divino (2015) fundamentados no modelo teórico proposto por Ho \& Saunders (1981) e estendido por Angbazo (1997), e com dados trimestrais em painel (estático e dinâmico), colhidos ex-post entre o primeiro trimestre de 2001 e o segundo trimestre de 2012, de 64 bancos brasileiros que possuem carteiras comerciais, analisaram o impacto de características específicas das instituições financeiras, das variáveis macroeconômicas e do índice de concentração de mercado de Herfindahl-Hirschaman (IHH). Como resultado, os autores encontraram uma relação significante e positiva para o puro spread (constante), custos administrativos, índice de cobertura, PIB, IHH e participação de mercado. Observaram também uma relação negativa e significante para as receitas de prestação de serviços, o que indica que bancos com maiores receitas de tarifas e comissões cobram spreads menores. Além disso, as variáveis índice de liquidez, tributação, risco de crédito, Selic, Índice de Preços ao Consumidor Amplo (IPCA), entre outras, não foram significantes. 
Silva et al. (2016), avaliando uma amostra com 135 bancos que operavam no mercado brasileiro entre 2003 a 2011 e o modelo de painel dinâmico Arellano-Bond (System-GMM), regrediram o spread bancário ou margem líquida de juros (NIM) contra a variável dependente defasada em um período, um vetor de variáveis que representam o market share dos bancos, um vetor com suas informações específicas e outro vetor de variáveis macroeconômicas, incluindo variáveis expectacionais, tais como, juros futuros, inflação esperada e PIB esperado. As variáveis que se apresentaram significantes e positivas foram o spread defasado, a participação de mercado, eficiência, risco de crédito, inflação, Selic, inflação esperada, juros futuros, capitalização em bolsa e volatilidade das taxas de câmbio. A única variável que se mostrou significante e com impacto negativo sobre o spread foi o tamanho dos bancos. Os indicadores de liquidez, custo de captação, índice de Basileia, PIB e PIB esperado não foram significantes.

Além dos estudos empíricos realizados, outros trabalhos se dedicaram a efetuar a decomposição contábil do spread como o desenvolvido por Assaf Neto (2004) no âmbito do mercado bancário do Brasil. Utilizando as demonstrações contábeis dos bancos, o autor identificou que o custo de captação representa $37,88 \%$ das taxas dos empréstimos, enquanto o "spread bruto" representa $62,12 \%$ das taxas dos empréstimos. Desse spread, foram retirados os impostos sobre as operações $(3,51 \%)$ e a inadimplência $(20,32 \%)$, chegando ao que foi denominado "spread direto", que representa $38,29 \%$ da taxa de juros. Por fim, foram retirados as despesas operacionais indiretas $(28,01 \%)$ e os tributos sobre o resultado - o Imposto de Renda de Pessoa Jurídica (IRPJ) e a Contribuição Social sobre o Lucro Líquido (CSLL) - (3,50\%), encontrando o "spread líquido" de 6,79\%, que representa o lucro dos bancos. Outra constatação interessante do estudo é que tanto as taxas de juros, quanto os diversos tipos de spread são maiores para pessoas físicas que para pessoas jurídicas.

Também realizando a decomposição do spread, considerando a taxa média do período compreendido entre 2011 e 2016 e utilizando os dados divulgados pelo BCB, Goldfajn (2017) encontrou um spread médio de $16,90 \%$, sendo $9,00 \%$ devido à inadimplência, $0,80 \%$ aos custos administrativos, $0,30 \%$ ao compulsório e ao Fundo Garantidor de Crédito (FGC), 2,7\% aos tributos sobre o resultado (CSLL e IRPJ) e 4,1\% referente ao lucro dos bancos.

A tentativa de encontrar os determinantes do spread bancário da economia brasileira também foi tema dos estudos de Aronovich (1994), Koyama \& Nakane (2002a), Koyama \& Nakane (2002b), Afanasieff et al. (2002), Guimarães (2002), Bignotto \& Rodrigues (2005) e Dantas et al. (2011). As variáveis significativas dos modelos implementados por esses autores e como elas impactam o valor do spread bancário são apresentadas, resumidamente, na Tabela 1.

O confronto com os principais resultados para os determinantes do spread bancário brasileiro mostra que os sinais obtidos neste artigo estão de acordo com os revelados pela literatura econômica. Dessa forma, é possível assegurar que as variáveis significativas ex-post do modelo e os seus efeitos estão dentro do previsto, o que é um indício inicial de que as estimativas obtidas são robustas. 
Tabela 1: Variáveis significativas e o sinal de seu impacto sobre o spread bancário brasileiro

\begin{tabular}{|c|c|c|c|}
\hline Artigo & Período & Spread & Variáveis significativas (sinal) \\
\hline Aronovich (1994) & \begin{tabular}{|l|}
$1986-1992$ \\
$1986-1992$
\end{tabular} \mid & Ex-ante & $\begin{array}{l}\text { Inflação }(+) \text {, choque econômico }(+) \\
\text { Inflação }(+) \text {, nível de atividade }(-)\end{array}$ \\
\hline $\begin{array}{l}\text { Koyama \& Na- } \\
\text { kane }(2002 a)\end{array}$ & $1996-2001$ & Ex-ante & $\begin{array}{l}\text { Inflação(+), produção industrial (-), taxa Se- } \\
\text { lic }(+) \text {, spread dos títulos públicos }(+) \text {, impos- } \\
\text { tos }(+) \text {, compulsório }(+) \text {, despesas adminis- } \\
\text { trativas }(+)\end{array}$ \\
\hline $\begin{array}{l}\text { Koyama \& Na- } \\
\text { kane }(2002 b)\end{array}$ & 1994-2001 & Ex-ante & $\begin{array}{l}\text { Taxa Selic(+), spread dos títulos públicos }(+) \text {, } \\
\text { impostos }(+) \text {, compulsórios }(+) \text {, despesas ad- } \\
\text { ministrativas }(+)\end{array}$ \\
\hline $\begin{array}{l}\text { Afanasieff } \\
\text { et al. }(2002)\end{array}$ & $\begin{array}{l}1997-2000 \\
1997-2000\end{array}$ & $\begin{array}{l}\text { Ex-ante } \\
\text { Ex-ante }\end{array}$ & $\begin{array}{l}\text { Despesas operacionais(+), receitas não fi- } \\
\text { nanceiras }(+) \text {, receita de serviços }(+) \text {, ban- } \\
\text { cos estrangeiros(-) } \\
\text { Inflação }(-) \text {, crescimento da produção in- } \\
\text { dustrial, taxa Selic }(+) \text {, spread de títulos pú- } \\
\text { blicos(+), impostos(+) }\end{array}$ \\
\hline $\begin{array}{l}\text { Guimarães } \\
(2002)\end{array}$ & $1995-2001$ & Ex-post & $\begin{array}{l}\text { Bancos estrangeiros (-), depósitos de curto } \\
\text { prazo }(+)\end{array}$ \\
\hline $\begin{array}{l}\text { Bignotto \& } \\
\text { Rodrigues } \\
\text { (2005) }\end{array}$ & 2001-2004 & Ex-ante & $\begin{array}{l}\text { Inflação(-), taxa Selic(+), despesas adminis- } \\
\text { trativas }(+) \text {, taxa de juros de risco(+), risco } \\
\text { de crédito }(+) \text {, participação de mercado(-), } \\
\text { liquidez(+), receita de serviços }(+) \text {, compul- } \\
\text { sório(+), total dos ativos }(+)\end{array}$ \\
\hline $\begin{array}{l}\text { Dantas et al. } \\
(2011)\end{array}$ & 2000-2009 & Ex-post & $\begin{array}{l}\text { Risco de crédito(+), participação de } \\
\text { mercado(-), } \operatorname{IHH}(+), \operatorname{PIB}(+)\end{array}$ \\
\hline Este artigo & $2009-2016$ & Ex-post & $\begin{array}{l}\text { Spread defasado(+), participação de mer- } \\
\text { cado(+), IHH(+), percentual de crédito }(-) \text {, } \\
\text { despesas operacionais e administrativas (+), } \\
\text { receitas não financeiras(-), imposto sobre o } \\
\text { resultado(+), provisões para crédito duvi- } \\
\text { doso(+), lucro líquido(+), compulsório de- } \\
\text { pósito à vista(-), compulsório depósitos a } \\
\text { prazo(+), índice de Basileia(+), bancos pú- } \\
\text { blicos(+), bancos com sede no exterior(+), } \\
\text { taxa Selic(-), desemprego(+), variação do } \\
\text { PIB(+), inflação(-) }\end{array}$ \\
\hline
\end{tabular}




\section{Requerimento de Capital - Acordos de Basileia}

Para compreender as razões pelas quais a implementação do Acordo de Basileia III poderia impactar de alguma forma o spread bancário, é necessário entender o que foram os acordos de Basileia e a sua importância para o sistema financeiro mundial, em particular, para o Sistema Financeiro Nacional (SFN).

O sistema bancário internacional é regulado por regras e limites que permitem todos os tipos de instituições financeiras participem do mercado sem impor riscos ao funcionamento da superestrutura financeira decorrente do processo de globalização. Os parâmetros básicos de liquidez e responsabilidade para todo o mercado são condensados nos Acordos de Basileia e estão em constante processo de aperfeiçoamento. Essa atualização das boas práticas é essencial para corrigir problemas que ameacem a estabilidade do sistema.

Os Acordos de Basileia sempre buscaram assegurar a estabilidade financeira, via requerimento de um percentual mínimo de capital próprio dos bancos, para a realização de operações de crédito. Esse requerimento é usualmente chamado de "índice de Basileia", por ter sido criado pelo Comitê de Supervisão Bancária de Basileia (BCBS), vinculado ao BIS (Bank for International Settlements), o Banco de Compensações Internacionais.

\subsection{Acordos de Basileia I e II}

O Acordo de Basileia I foi fechado em 1988, oficialmente denominado International Convergence of Capital Measurement and Capital Standards, tendo como foco a prevenção contra o risco de crédito, via reserva de capital, e a limitação da capacidade de alavancagem dos bancos. Assim, ele contribui para a estabilidade do sistema bancário nacional, valendo-se de quatro pilares: i) definição de capital nível 1 e capital nível 2; ii) implementação de um fator de ponderação do risco; iii) alocação mínima de capital de $8 \%{ }^{1}$, sendo no mínimo $4 \%$ de capital nível 1; e iv) implementação progressiva. Somente em 1996, o Comitê incorporou o risco de mercado ao acordo.

Em 2004, o BCBS divulgou a revisão do primeiro acordo de Basileia, que ficou conhecido como Basileia II. O objetivo era buscar uma mensuração mais precisa para os riscos incorridos, além de melhorar a transparência das informações dos bancos e aprimorar o processo de supervisão. Esse acordo incluiu a i) exigência de capital mínimo para os riscos de mercado e operacional, além do já requerido para risco de crédito; e a ii) determinação de disciplina de mercado, demandando transparência na divulgação de informações e transparência de mercado. Esse acordo ainda está em processo de implementação em diversas partes do mundo, inclusive no Brasil.

\subsection{Basileia III}

A crise financeira mundial, iniciada em 2007, mostrou que as exigências dos acordos de Basileia I e II não eram suficientes para inibir a alavancagem excessiva dos bancos, o que, em conjunto com a baixa qualidade do capital e a diminuta margem de liquidez, contribuíram para fragilizar o sistema bancário mundial. Diante disso, fez-se necessário revisar a estrutura prudencial

\footnotetext{
${ }^{1} \mathrm{O}$ Banco Central do Brasil foi mais conservador na aplicação do Acordo de Basileia I e estipulou que a alocação mínima de capital para os bancos brasileiros seria de $11 \%$.
} 
aplicável às instituições financeiras, dando origem a dois documentos ${ }^{2}$ que ficaram conhecidos como Basileia III.

O principal objetivo desse acordo é preparar os bancos para suportarem os impactos de choques advindos do próprio sistema financeiro ou de outros setores da economia, evitando que os impactos de crises financeiras se alastrem para a economia real. O foco do Acordo Basileia III é melhorar a qualidade da estrutura do capital dos bancos e, para isso, revisou os instrumentos aceitos como de nível 1, além de o subdividir em duas partes: a parcela de capital principal e a parcela de capital adicional. O capital principal é o de melhor qualidade sendo composto praticamente apenas de ações ordinárias e lucros acumulados, e sendo abatidas, ainda, as deduções regulatórias.

Além disso, foram criados os buffers de capital principal: o contracíclico que visa compensar a tendência de Basileia II de acentuar flutuações cíclicas da economia; o de conservação, que representa um "colchão" extra de capital para absorver possíveis perdas; e o sistêmico, que será exigido dos grandes bancos que, devido ao seu porte, poderiam gerar risco ao sistema financeiro em caso de insolvência. Cabe mencionar que o capital de nível 2 continua existindo, sendo composto por instrumentos de dívidas que não possuem a liquidez necessária para serem enquadrados como de nível 1.

No Brasil, o acordo de Basileia III foi implementado por meio de um conjunto de normas (resoluções, circulares e cartas circulares) editadas pelo BCB a partir de 2013. Essas normas introduziram, entre outras coisas, os novos requerimentos mínimos de capital principal, capital nível 1, patrimônio de referência e adicional de capital principal (Resolução ${ }^{\circ} 4.193$, de março de 2013). Desde a implementação do primeiro acordo de Basileia, o BCB adota uma postura conservadora em relação à exigência de capital aos bancos que operam no país.

Enquanto internacionalmente o patrimônio de referência mínimo, antes desse acordo, era de $8 \%$, no Brasil foi adotado o índice mínimo de $11 \%$. Com a advento do Basileia III, todos os países que aderiram ao acordo, tinham que adotar padrões mais conservadores, podendo chegar à uma exigência de $13 \%$. Em relação ao capital principal e ao capital nível 1, o aumento da exigência é ainda mais significativo, o que pode exigir um esforço de adequação dos bancos. Essas adaptações quanto às exigências são chamadas de ajustes prudenciais e as diferenças de requisitos de percentual mínimo de capital são apresentadas na Tabela 2.

Tabela 2: Diferenças nas exigências de percentual mínimo de capital dos acordos de Basileia I (Brasil), Basileia II e Basileia III - \%

\begin{tabular}{l|ccc}
\hline Tipo de Capital & $\begin{array}{c}\text { Basileia I } \\
\text { (Brasil) }\end{array}$ & Basileia II & Basileia III \\
\hline Capital Principal & $4,7 \%^{*}$ & $2 \%^{*}$ & $7 \%-9 \%$ \\
Capital Nível 1 & $5,5 \% *$ & $4 \%^{*}$ & $8,5 \%-11 \%$ \\
Patrimônio de Referência (PR) & $11 \%$ & $8 \%$ & $10,5 \%-13 \%$ \\
\hline
\end{tabular}

Nota: ${ }^{*}$ Limites implícitos.

Fonte: BCB.

\footnotetext{
${ }^{2}$ Os dois documentos que compõe o Basileia III são: A global regulatory framework for more resilient banks and banking systems e Basel III: International framework for liquidity risk measurement, standards and monitoring.
} 
Além das mudanças referentes à quantidade de capital (percentual mínimo), a qualidade do capital também foi observada pelo regulador nacional na implementação de Basileia III $^{3}$. Nesse sentido, instrumentos (menos líquidos) que eram considerados como capital antes de Basileia III, deixaram de ser após sua implementação. Importante destacar, também, que esse impacto não foi imediato, pois, esses ajustes prudenciais foram feitos de forma escalonada entre 2014 e 2019. Adicionalmente, as deduções regulamentares ou ajustes prudenciais, que anteriormente incidiam sobre o patrimônio de referência total, passaram a ser aplicadas ao capital principal.

Em face das mudanças solicitadas, é correto esperar que aqueles bancos cuja a estrutura de capital estava mais próxima às novas determinações não devem fazer grandes esforços para se adaptar, mas outros, como bancos que possuem instrumentos híbridos de capital e dívida que deixaram de ser considerados como capital de maior qualidade, precisam adotar estratégias para reforçar o seu capital principal, como distribuir menos dividendos, para conseguir moldar-se às novas regras dentro do cronograma de transição estabelecido pelo BCB. De acordo com Pinheiro \& Savoia (2014), a maior parte das instituições financeiras brasileiras possui baixa alavancagem, o que as favorece no processo de adequação às novas regras.

O Acordo de Basileia III foi implementado no país de forma escalonada, conforme demonstrado na Tabela 3, de forma a completar o período de transição em 2019.

Tabela 3: Cronograma de Implementação do acordo de Basileia III no Brasil percentual mínimo de capital - \%

\begin{tabular}{c|c|c|c|c|c|c|c}
\hline Tipo de Capital & 2013 & 2014 & 2015 & 2016 & 2017 & 2018 & 2019 \\
\hline $\begin{array}{c}\text { Capital Principal } \\
\text { (mínimo + adicional) }\end{array}$ & $4,50 \%$ & $4,50 \%$ & $4,50 \%$ & $\begin{array}{c}5,125 \% \text { a } \\
5,75 \%\end{array}$ & $\begin{array}{c}5,75 \% \text { a } \\
7,00 \%\end{array}$ & $\begin{array}{c}6,375 \% \text { a } \\
8,28 \%\end{array}$ & $\begin{array}{c}7,00 \% \text { a } \\
9,50 \%\end{array}$ \\
\hline $\begin{array}{c}\text { Capital Nível 1 } \\
\text { (mínimo + adicional) }\end{array}$ & $5,50 \%$ & $5,50 \%$ & $5,50 \%$ & $\begin{array}{c}6,625 \% \mathrm{a} \\
7,25 \% \mathrm{a} \\
7,25 \%\end{array}$ & $\begin{array}{c}7,50 \% \\
8,50\end{array}$ & $\begin{array}{c}8,50 \% \mathrm{a} \\
9,75 \%\end{array}$ & $11,00 \%$ \\
\hline $\begin{array}{c}\text { Patrimônio de } \\
\text { Referência (PR) } \\
\text { (mínimo + adicional) }\end{array}$ & $11,00 \%$ & $11,00 \%$ & $11,00 \%$ & $\begin{array}{c}10,50 \% \text { a } \\
11,125 \%\end{array}$ & $\begin{array}{c}10,50 \% \mathrm{a} \\
11,75 \%\end{array}$ & $\begin{array}{c}10,50 \% \mathrm{a} \\
12,375 \%\end{array}$ & $\begin{array}{c}10,50 \% \mathrm{a} \\
13,00 \%\end{array}$ \\
\hline
\end{tabular}

Fonte: BCB.

É importante destacar que nas Tabelas 2 e 3 não foi considerado o adicional de capital principal. Mesmo assim, nota-se que os aumentos na exigência de capital principal e de capital nível 1 são maiores que o aumento no patrimônio de referência. Na Figura 1, por sua vez, é possível verificar o esforço dos bancos comerciais brasileiros de se adequarem às novas exigências de estrutura de capital. Comparando o percentual de capital observado em junho de 2014 e em junho de 2016, é possível perceber aumento nos indicadores do Índice de Basileia, Capital de nível 1 e de Capital principal.

\footnotetext{
${ }^{3} \mathrm{O}$ Capital Principal é formado primordialmente pelas ações (ordinárias e preferenciais, desde que não resgatáveis e sem cumulatividade de dividendos), reservas de capital e lucros acumulados, representando, portanto, a parcela de maior qualidade e mais apta a absorver perdas. Sobre esse montante são feitas todas as deduções regulamentares. O capital complementar de nível I e o capital de nível II são compostos por instrumentos de dívida subordinada (perpétua, no primeiro caso, e com mais de 5 anos, no segundo) e, para comporem o Patrimônio de Referência, devem passar por processo de aprovação no BCB. Disponível em <http://www.bcb.gov.br/fis/super visao/basileia.asp>, em 18/02/2017.
} 
Figura 1: Comparativo do percentual de capital dos bancos comerciais brasileiros, por categoria - junho de 2014 e junho de 2016 - \%

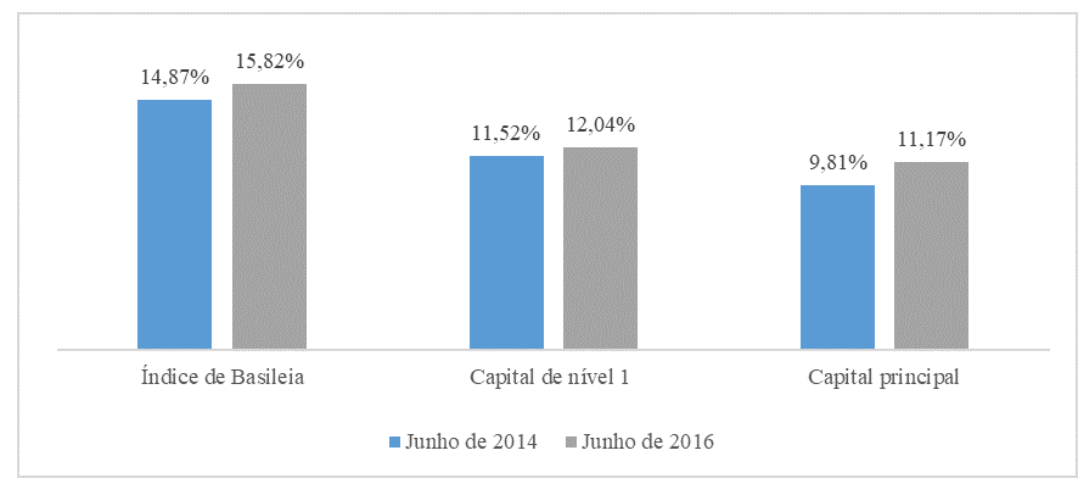

Fonte: Dados do BCB, cálculo efetuado pelo autor.

Fica evidente que essas medidas fizeram com que as instituições financeiras planejassem melhor suas estratégias da concessão de crédito de forma a otimizar a relação entre retorno e risco de cada contrato, além de ampliar a necessidade de capitalização. Esse processo, no entanto, poderá dar início a um novo ciclo de fusões aquisições de bancos de pequeno e médio porte ( $\mathrm{Pi}$ nheiro \& Savoia 2014), bem como estimular o mercado de securitização, uma solução adotada pelas instituições menores em momentos de restrição à liquidez, mas que tem alcance limitado. Por fim, também é possível que os banco de pequeno e médio porte busquem alternativas de serviços de forma a operar em nichos de mercado onde eles tenham vantagens comparativas.

\subsection{Basileia III e o Spread bancário}

O Acordo de Basileia III, conforme mencionado anteriormente, eleva a exigência de capital, e também da qualidade desses recursos, a fim de tornar mais resiliente o sistema bancário dos países. Para se adequar, dentre as estratégias que os bancos dispõem para aumentar seu capital, destacam-se a emissão de novas ações e a retenção de lucros.

Entretanto, ao implementar a mudança na sua estrutura de capital, os bancos modificam os seus custos de operação, o que, consequentemente, tende a afetar o spread bancário praticado. O impacto poderia ser decorrente do aumento das taxas de juros ou mediante uma maior seletividade na contratação das operações de crédito, sendo que cada uma das opções mencionadas tem um efeito distinto sobre o spread. A primeira estimularia um aumento do spread, enquanto a segunda, a sua queda.

Além disso, na Basileia III foram criados os buffers de capital principal, que funcionam como um o contracíclico e que visam compensar a tendência de acentuar flutuações cíclicas da economia observadas no Basileia II, e os de conservação, que representam um "colchão" extra de capital para absorver possíveis perdas.

Bichsel et al. (2019) analisaram o impacto de maiores requisitos de capital bancário sobre os spreads de empréstimos corporativos e determinaram que um aumento de um ponto percentual nos índices de capital leva a um aumento do spread de até 5 pontos base, quando ponderado pelo risco, e de até 20 pontos base sem a referida ponderação. Da mesma forma, os autores mos- 
tram que a introdução gradual dos requisitos regulatórios é benéfica para o sistema bancário dado que, em uma implementação imediata, os bancos deficitários tenderão a cobrar spread ainda maiores em relação às instituições com superávits. Diante desses resultados, é factível esperar que as modificações introduzidas pelo acordo de Basileia III devem impactar positivamente o spread bancário brasileiro, resultado condizente com os observados neste artigo.

De acordo com Chun et al. (2012), as exigências de spreads de empréstimos variam entre os diferentes modelos de negócios dos bancos e entre os países. Para evitar que o retorno sobre o patrimônio diminua, os spreads devem ser elevados em 0,1 pontos base para bancos imobiliários e hipotecários e chegam a até 9,1 pontos base para bancos comerciais durante os períodos de amostra de 2005-2010. Países como Brasil, China, Índia e México exigem que seus bancos tenham grandes spreads de empréstimos que podem variar de 13,2 a 29,7 pontos base.

As maiores exigências de capital produzem efeitos macroeconômicos que podem variar conforme a abordagem escolhida. Angelini et al. (2011) mostram que, a cada aumento de ponto percentual no índice de capital, há um declínio médio de $0,09 \%$ na produção em estado estacionário em relação ao nível base. Já Caggiano \& Calice (2011), estudando o impacto do Basileia III sobre as economias africanas, afirmam que índices de capital mais elevados podem fortalecer a resiliência dos sistemas bancários e, assim, promover ganhos de bem-estar no longo prazo para a população.

Aumento das taxas de juros cobradas, com consequente aumento do spread

O Retorno sobre o Capital Exigido (RSCE) é uma métrica de performance utilizada pelos bancos para mensurar a rentabilidade de suas operações, em conjunto com a eficiência na alocação do capital. Essa métrica se assemelha ao Risk Adjuted Return on Capital (RAROC), mas utiliza em seu denominador o capital padronizado requerido pelo regulador.

Considerando o maior requerimento de capital advindo do Acordo de Basileia III, com vistas a manter o seu RSCE, os bancos teriam que elevar seus spreads. Além disso, o conceito de RSCE poderia ser replicado para as parcelas de capital que estão sendo mais impactadas pelo Acordo de Basileia III, com o advento de duas novas métricas de rentabilidade: o Retorno sobre o Capital Principal e o Retorno sobre o Capital Nível 1. A Figura 2 ilustra essa possível relação.

Figura 2: Relação do Acordo de Basileia III sobre o Spread

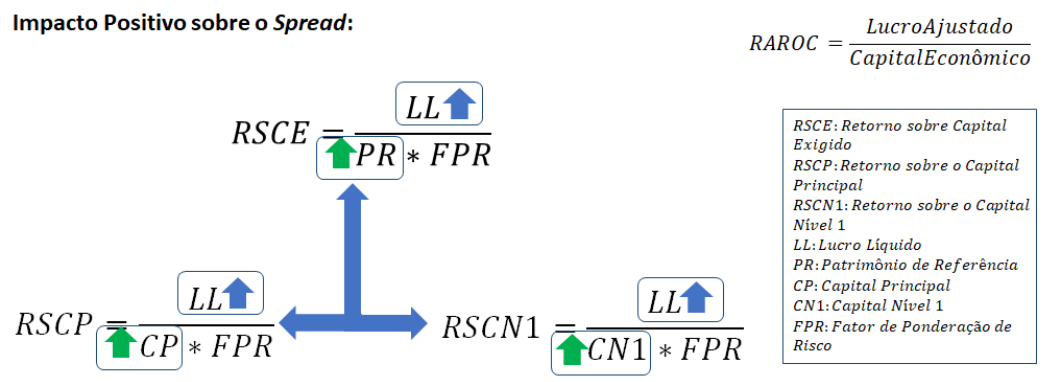

Fonte: Elaboração própria. 
Partindo da premissa de que o lucro líquido dos bancos faz parte da composição do spread, com a elevação da exigência de capital, o lucro teria que ser elevado para a manutenção dos diversos tipos de retorno sobre o capital, e, consequentemente, o spread também aumentaria.

Redução dos spreads devido a uma maior seletividade na contratação das operações de crédito

Alternativamente, os bancos poderiam optar por concentrar suas operações de crédito em linhas e clientes com riscos menores, que consomem menos capital (Fator de Ponderação de Risco (FPR) menor). Essa maior seletividade na escolha das operações poderia implicar na redução do spread, pois clientes com níveis de risco menores, poderiam não estar dispostos a pagar juros altos. Além disso, com uma redução maior no FPR do que na exigência dos diversos tipos de capital, seria possível manter o retorno.

Embora também seja possível, aumentar a seletividade da carteira de clientes é mais difícil de implementar, pois dificilmente os bancos conseguiriam informações suficientes para avaliar o perfil de seus clientes e as operações em um curto espaço de tempo não permitem uma correta avaliação do indivíduo com quem se está transacionando. Para tentar manter o retorno das operações, seria mais fácil efetuar o ajuste via aumento do spread bancário. A Figura 3 ilustra essa possível relação.

Figura 3: Relação do Acordo de Basileia III sobre o Spread

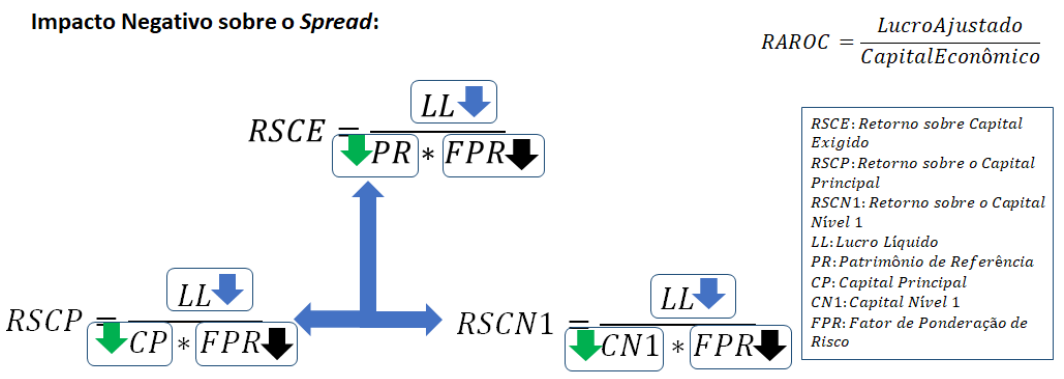

Fonte: Elaboração própria.

\section{Metodologia}

\subsection{Dados}

Neste artigo, foram utilizados dados de 73 bancos comerciais ${ }^{4}$ com carteiras de crédito ativas no período compreendido entre o segundo trimestre de 2009 e o segundo trimestre de 2016, totalizando 2.117 observações. Os dados específicos de cada instituição foram colhidos no ambiente que disponibiliza "informações para análise econômico-financeira" no site do BCB. Do relatório "50 maiores bancos e o consolidado do Sistema Financeiro Nacional", foram retiradas as informações do período compreendido entre o segundo trimestre de 2009 e o primeiro trimestre de 2014. Os dados dos demais trimestres foram retirados do "IF.Data - Dados selecionados de entidades supervisionadas".

\footnotetext{
${ }^{4} \mathrm{~A}$ lista completa das instituições que fizeram parte da amostra está disponível no Anexo I.
} 
As séries macroeconômicas foram obtidas no sítio do IPEA data. A série de inflação é calculada com base na variação do IPCA. A série mensal foi acumulada para cada trimestre e dessazonalizada com a utilização do filtro Census $\mathrm{X}-12$. A taxa de desemprego foi obtida do Seade/PED para o fechamento de cada trimestre e dessazonalizada com a utilização do filtro Census X-12. A variação do PIB foi obtida no IBGE com periodicidade trimestral, tendo sua série deflacionada com base na variação do IPCA e dessazonalizada com a utilização do filtro Census X-12. Após esses procedimentos, foi calculada a variação trimestral do indicador. A Selic foi coletada no BCB com periodicidade mensal, que foram acumuladas para cada trimestre.

Antes de realizar as regressões, os dados foram transformados em fatores (adicionando 1) e, posteriormente, foi calculado o logaritmo. Na Tabela 4, são apresentadas as estatísticas descritivas das variáveis incluídas no modelo.

Tabela 4: Estatísticas descritivas das variáveis incluídas no modelo

\begin{tabular}{l|c|c|c|c}
\hline Variável & Média & $\begin{array}{c}\text { Desvio } \\
\text { Padrão }\end{array}$ & Mínimo & Máximo \\
\hline Spread & 0,1735 & 0,0323 & $-0,0391$ & 0,2122 \\
Market share & 0,0126 & 0,0396 & 0,0000 & 0,2311 \\
IHH & 0,1408 & 0,0091 & 0,0130 & 0,1560 \\
Participação do crédito & 0,3084 & 0,1604 & 0,0000 & 0,7009 \\
Despesas Administrativas e Operacionais & 0,0276 & 0,0265 & 0,0013 & 0,3132 \\
Receitas não Financeiras & 0,0171 & 0,0261 & 0,0060 & 0,4152 \\
Provisões contra Créditos Duvidosos & 0,0218 & 0,0253 & 0,0000 & 0,2813 \\
Impostos (tributos) sobre o Resultado & 0,0007 & 0,0111 & $-0,2060$ & 0,2054 \\
Lucro Líquido & 0,0017 & 0,0256 & $-0,6307$ & 0,1291 \\
Compulsório sobre Depósitos à vista & 0,0139 & 0,0207 & 0,0000 & 0,1767 \\
Compulsório sobre Depósitos a prazo & 0,0759 & 0,0550 & 0,0000 & 0,2337 \\
Índice de Basileia & 0,2281 & 0,2263 & $-0,3038$ & 220,0020 \\
Selic & 0,0250 & 0,0047 & 0,0164 & 0,0338 \\
Variação do PIB & 0,0078 & 0,0139 & $-0,0267$ & 0,0477 \\
Desemprego & 0,0897 & 0,0137 & 0,0770 & 0,1313 \\
Inflação & 0,1631 & 0,0051 & 0,0074 & 0,0326 \\
\hline
\end{tabular}

Fonte: Elaboração própria.

\subsection{Modelo Econométrico}

Neste estudo, buscamos identificar os determinantes do spread bancário, em particular, estamos interessados em analisar os efeitos da implementação do Acordo de Basileia III ${ }^{5}$. Porém, os dados disponíveis para o indicador do Acordo de Basileia III (Capital de Nível 1 e o Capital Principal) só começaram a ser divulgados pelo Banco Central apenas a partir do segundo trimestre de 2014. Com um período menor e para garantir os graus de liberdade nas estimações, seguimos a estratégia de estimar os efeitos do Acordo de Basileia III em duas etapas. É importante mencionar que esse período foi escolhido de forma que todos os bancos avaliados tivessem as mesmas informações em todos os trimestres com o objetivo de ter uma base de dados do tipo painel balanceado.

\footnotetext{
${ }^{5} \mathrm{~A}$ implementação do acordo no Brasil, no que tange à alocação de capital para risco de crédito - ainda que em fase avançada no período avaliado neste artigo - se completou apenas em 2019.
} 
A primeira regressão considerou todos os períodos da amostra (2009T2 a 2016T2) e testou a significância de todas as variáveis do modelo com o objetivo de utilizar a informação disponível (base completa) para identificar as variáveis significativas para determinar o spread bancário no Brasil. Assim, os resultados puderam ser usados na segunda etapa. A segunda etapa restringe o período de análise àquele voltado para a implementação da resolução, ínterim compreendido entre o segundo trimestre de 2014 e o segundo trimestre de 2016, inserindo apenas os determinantes relevantes encontrados na etapa anterior no modelo voltado para estimar os efeitos do acordo de Basileia III, o percentual de capital nível 1 (CN1) e o percentual de capital principal (CP) no modelo econométrico.

Assim, como os diversos modelos apresentados na revisão teórica deste artigo, o modelo dinâmico ora apresentado, defende que o spread praticado no Brasil pode ser explicado por variáveis representativas do nível de concentração do mercado, por variáveis indicativas das características de cada banco e pelo comportamento de algumas variáveis macroeconômicas. Como a origem dos dados do modelo é ex-post, também foi incluída uma defasagem da variável dependente, pois acredita-se que, pelo fato de grande parte das operações de crédito dos bancos possuírem taxas prefixadas, o spread ex-post não poderia ser alterado em apenas um trimestre, existindo alguma persistência nessa variável.

As variáveis inseridas no modelo de regressão da primeira etapa foram escolhidas a partir das pesquisas empíricas e decomposições contábeis do spread apresentadas na segunda seção deste artigo, resultando na equação (1).

$$
\begin{aligned}
\ln S P_{i t}=\beta_{0} & +\beta_{1} \ln S P_{i t-1}+\beta_{2} \ln M S_{i t}+\beta_{3} \ln I H H_{t}+\beta_{4} \ln P C_{i t} \\
& +\beta_{5} \ln D O A_{i t}+\beta_{6} \ln R N F_{i t}+\beta_{7} \ln P C D_{i t}+\beta_{8} \operatorname{lnI} R_{i t} \\
& +\beta_{9} \ln L L_{i t}+\beta_{10} \ln I B_{i t}+\beta_{11} \ln C V_{i t}+\beta_{12} \ln C P Z_{i t} \\
& +\beta_{13} \ln S E L I C_{t}+\beta_{14} \ln D E S E M P_{t}+\beta_{15} \ln P I B_{t} \\
& +\beta_{16} \ln I P C A_{t}+\beta_{17} D P U B+\beta_{18} D E X T+\eta_{i}+\varepsilon_{i t}
\end{aligned}
$$

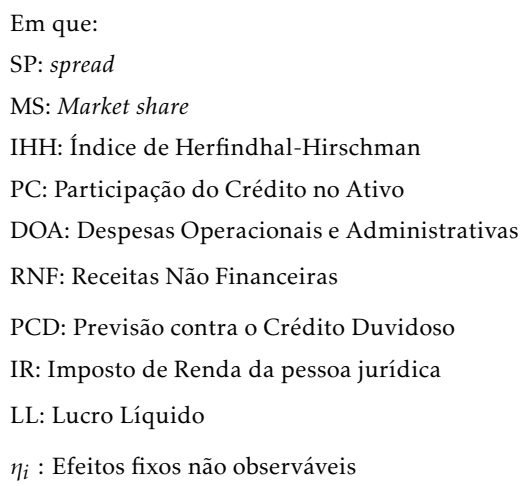

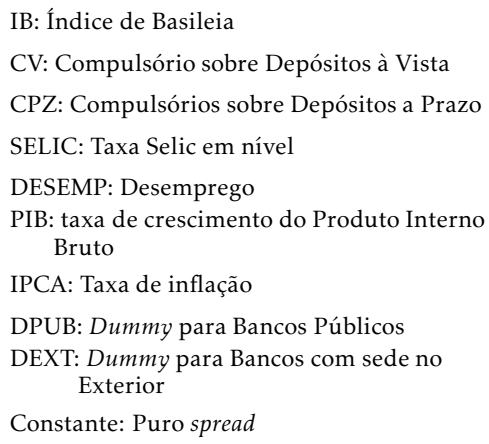

Como indicado anteriormente, nessa etapa de estimação, serão considerados os dados trimestrais de 73 bancos comerciais brasileiros no período compreendido entre o segundo trimestre de 2009 e o segundo trimestre de 2016. É importante registrar que esses bancos operaram em todos os 29 trimestres, constituindo-se um painel balanceado. Ressalte-se que o spread, ou NIM, foi 
calculado a partir de uma adaptação para modelos em painel da fórmula $4 \mathrm{w}$, proposta por Brock \& Suarez (2000) e apresentada na equação (2). Nela, o spread é calculado para cada banco em cada período conforme descrito na equação (3).

$$
\begin{gathered}
4 w=\left(\frac{\text { Juros Recebidos }- \text { Juros Pagos }}{A t_{j}}\right) \\
\text { Spread }_{i t}=\left(\frac{\text { RIF }_{i t}-\text { DIF }_{i t}}{\text { Ativo }_{i t}}\right)
\end{gathered}
$$

em que $R I F_{i t}$ é a receita de intermediação financeira do banco $i$ no período $t$, e $D I F_{i t}$ a sua despesa de intermediação financeira nas mesmas condições. $\mathrm{O}$ principal motivo para a escolha da desta fórmula é a forma de disponibilização dos dados nos relatórios disponíveis. Cabe registrar que as despesas com operações de câmbio e com a provisão sobre o crédito duvidoso não foram consideradas na apuração das despesas de intermediação financeira e que as receitas com câmbio também foram excluídas das receitas de intermediação financeira.

\section{Resultados}

O estudo econométrico baseia-se em um painel dinâmico e na aplicação do método conhecido como GMM System ${ }^{6}$, associado aos trabalhos realizados por Arellano \& Bond (1991), Arellano \& Bover (1995) e Blundell \& Bond (1998). A utilização de modelos dinâmicos permite o uso de defasagens da variável dependente como regressores, além da possibilidade de utilização das variáveis explicativas também defasadas. Essa característica é muito útil, pois os bancos não podem alterar totalmente o spread bancário em apenas um trimestre, devido à característica de longo prazo de alguns contratos de captação e, principalmente, de crédito. Em muitos casos, são pactuadas taxas de juros que não podem ser alteradas a qualquer momento pelas instituições financeiras, sejam elas pós ou prefixadas.

Para que os resultados fossem mais robustos, optou-se por utilizar o GMM System two-step, pois este método é assintoticamente mais eficiente. Contudo, uma limitação do método é que ele tende a produzir erros-padrão viesados para baixo, problema corrigido por meio da matriz de covariância derivada por Windmeijer (2005) de forma a tornar as estimações robustas do two-step mais eficientes do que as robustas do one-step.

Para que o método funcione corretamente, é preciso verificar a validade das condições de momento. Para isso, foram realizados os testes de sobreidentifição de Hansen para verificar se os instrumentos são válidos e o teste difference-Hansen para avaliar a exogeneidade dos grupos particulares de instrumentos. Além disso, será efetuado o teste z de autocorrelação dos resíduos de Arellano \& Bond (1991), conhecido como AR (2).

\footnotetext{
${ }^{6}$ Embora o Modelo GMM System possa trabalhar com painel não balanceado, o que permitiria também tratar as fusões e aquisições no estudo, consideramos neste trabalho apenas bancos que atuam com crédito e com informação completa ao longo do período (painel balanceado).
} 


\subsection{Testes de Raiz unitária - Variáveis em Painel}

Como trata-se de uma estimação com vários períodos, é preciso verificar a estacionariedade das séries incluídas no modelo. Foram efetuados os testes de raiz unitárias de Levin-Lin-Chu (LLC) e Im-Pesaran-Shin (IPS) próprios para painel. Já para as séries macroeconômicas que não variam de banco para banco, aplicou-se o teste Ng Peron. É importante destacar que, a partir desse momento, as variáveis serão consideradas em logaritmo para que seja capturada a elasticidade do spread em relação às demais variáveis.

Os testes de raiz unitária LLC e o IPS possuem como hipótese nula a não estacionariedade da série. O teste LLC é indicado para painéis balanceados com quantidade de indivíduos entre 10 e 250 , e de 25 a 250 observações por indivíduo. A maior limitação do LLC é assumir que todas as variáveis explicativas possuem o mesmo coeficiente, sendo sua hipótese alternativa a de que todas as séries são estacionárias, o que é uma hipótese muito restritiva. O teste IPS supre parcialmente essa limitação, pois mantém a hipótese nula de que todos as séries possuem raiz unitária, mas a hipótese alternativa é que uma fração (pelo menos uma) das séries não possua raiz unitária. A quantidade de lags a ser utilizada nos testes foi calculada de acordo com o método Akaike Information Criterion (AIC), limitado à quantidade máxima de 6 lags.

Os resultados dos testes são apresentados na Tabela 5, na qua pode-se observar que pelo menos um dos testes rejeitou a hipótese nula de raiz unitária para todas as séries, o que indica que as variáveis podem ser utilizadas no modelo.

\subsection{Testes de Raiz Unitária - Séries Temporais}

Para as séries cujos dados variam apenas com o tempo, mas não variam de banco para banco, foi efetuado o teste de raiz unitária Ng Peron, com o método de estimação AR GLS-detrended. A quantidade de lags utilizada nos testes foi calculada de acordo com o método Modified Akaike, também limitado à quantidade máxima de 6 lags. Os resultados do teste são apresentados na Tabela 6 e confirmam que as séries são estacionárias, o que viabiliza seu uso nas regressões.

\subsection{Estimação dos modelos da primeira etapa}

A primeira etapa abrange todos os períodos da amostra para estimar o modelo dinâmico (1). Ambas as regressões foram feitas a partir do método de GMM-System two steps robusto. As regressões implementadas na primeira etapa, que consideram o período mais abrangente compreendido entre o segundo trimestre de 2009 e o segundo trimestre de 2016, tem como objetivo identificar as principais variáveis que explicam o spread bancário praticado no Brasil. O teste AR(2) de Arellano \& Bond (1991) indicou que não há autocorrelação entre os erros. Os testes de Hansen e Difference-in-Hansen também foram bem-sucedidos, indicando que os instrumentos são válidos. Para evitar uma grande perda de graus de liberdade, a quantidade de instrumentos foi truncada, sendo considerados apenas a segunda e terceira lags do spread. Os resultados são apresentados na Tabela 7 .

Conforme esperado, as despesas operacionais e administrativas (DOA), os impostos sobre o resultado (IR), o lucro líquido dos bancos (LL), os depósitos compulsórios sobre depósitos a prazo (CPZ) e o desemprego (DESEMP) foram 
Tabela 5: Resultado dos Testes de Raiz Unitária LLC e IPS para as variáveis em Painel Variáveis

\begin{tabular}{|c|c|c|c|c|c|}
\hline \multirow[b]{2}{*}{ Variáveis } & \multicolumn{2}{|c|}{ LLC - Estatística $t^{*}$} & \multicolumn{2}{|c|}{ IPS - Estatística $t^{*}$} & \multirow[b]{2}{*}{$\begin{array}{l}\text { Lags } \\
\text { (AIC) }\end{array}$} \\
\hline & $\begin{array}{l}\text { Com constante e } \\
\text { sem tendência }\end{array}$ & $\begin{array}{c}\text { Sem constante e } \\
\text { sem tendência }\end{array}$ & $\begin{array}{l}\text { Com constante e } \\
\text { sem tendência }\end{array}$ & $\begin{array}{l}\text { Sem constante e } \\
\text { sem tendência }\end{array}$ & \\
\hline Spread & $-0,3104$ & $-6,5666^{* * *}$ & $-7,2159^{* * *}$ & $-11,8636^{* * *}$ & 2,25 \\
\hline Market share & $-2,7932^{* * *}$ & $-6,5648^{* * *}$ & 0,8617 & 1,6072 & 1,37 \\
\hline $\begin{array}{c}\text { Participação do } \\
\text { Crédito }\end{array}$ & $-3,5321^{* * *}$ & $-1,7195^{* *}$ & $-2,3997^{* *}$ & $-2,2996^{* *}$ & 0,85 \\
\hline $\begin{array}{c}\text { Despesas Operac. } \\
\text { e Adm }\end{array}$ & 13,5758 & $-2,9500^{* *}$ & $-4,0231^{* * *}$ & $-6,8101^{* * *}$ & 2,53 \\
\hline $\begin{array}{c}\text { Receitas Não } \\
\text { Financeiras }\end{array}$ & 4,7672 & $-3,4437^{* * *}$ & $-7,5694^{* * *}$ & $-6,8459^{* * *}$ & 2,78 \\
\hline $\begin{array}{c}\text { Provisões para o } \\
\text { Crédito }\end{array}$ & 2,0079 & $-1,7020^{* *}$ & - & $-2,6304^{* * *}$ & 1,45 \\
\hline $\begin{array}{c}\text { Tributos sobre o } \\
\text { Resultado }\end{array}$ & $-12,5386^{* * *}$ & $-16,9265^{* * *}$ & $-14,6253^{* * *}$ & $-13,7055^{* * *}$ & 1,56 \\
\hline $\begin{array}{l}\text { Lucro } \\
\text { Líquido }\end{array}$ & $-5,2177^{* * *}$ & $-7,9251^{* * *}$ & $-10,6306^{* * *}$ & $-10,5921^{* * *}$ & 2,56 \\
\hline $\begin{array}{l}\text { Compulsório } \\
\text { Dep. à Vista }\end{array}$ & $-6,2385^{* * *}$ & $-8,6560^{* * *}$ & $-10,0384^{* * *}$ & $-5,3279^{* * *}$ & 1,29 \\
\hline $\begin{array}{l}\text { Compulsório } \\
\text { Dep. a Prazo }\end{array}$ & $3,8463^{* * *}$ & $-0,0769$ & - & $-4,3178^{* * *}$ & 1,85 \\
\hline $\begin{array}{l}\text { Índice de } \\
\text { Basileia }\end{array}$ & $-7,2843^{* * *}$ & $-5,8755^{* * *}$ & $-8,8033^{* * *}$ & $-2,3802^{* * *}$ & 1,16 \\
\hline
\end{tabular}


Tabela 6: Resultado do Teste de Raiz Unitária Ng Peron para as variáveis em Série Temporal

\begin{tabular}{c|c|c|c|c|c}
\hline Série & Mza & Mzt & MSB & MPT & Lag Length \\
\hline Desemprego & $-23,0484^{* * *}$ & $-3,1138^{* * *}$ & $0,13521^{* * *}$ & $1,9587^{* *}$ & 2 \\
SELIC & $-36,6183^{* * *}$ & $-4,11222^{* * *}$ & $0,11230^{* * *}$ & $1,1343^{* * *}$ & 1 \\
IHH & $-9,925^{* *}$ & $-2,04359^{* *}$ & $0,20600^{* *}$ & $3,14753^{* *}$ & 4 \\
PIB & $-8,18027^{* *}$ & $-2,01842^{* *}$ & $0,24674^{*}$ & $3,00983^{* *}$ & 0 \\
Inflação & $-11,2662^{* *}$ & $-2,36193^{* *}$ & $0,20965^{* *}$ & $2,2189^{* *}$ & 0 \\
\hline
\end{tabular}

Nota: ${ }^{* * *},{ }^{* *},{ }^{*}$, denotam significância de $1 \%, 5 \%$ e $10 \%$, respectivamente.

significantes e afetaram o spread positivamente, a um nível de significância de $1 \%$. Os resultados demostraram um forte impacto das despesas operacionais e administrativas sobre o spread. Resultados semelhantes foram encontrados por Almeida \& Divino (2015) e Manhiça \& Jorge (2012), entre outros. O spread defasado também foi significante a $1 \%$, o que pode ser explicado pela origem dos dados ser ex-post, onde existe uma persistência do indicador ao longo do tempo.

A taxa Selic e a inflação apresentaram coeficientes negativos e significantes a $1 \%$. Particularmente em relação à taxa Selic, uma possível explicação para o sinal negativo é o fato dos passivos dos bancos serem mais indexados a essa taxa que os ativos, que possuem um percentual considerável de operações com taxas prefixadas. Assim, um aumento da Selic em t, tende a impactar de forma mais rápida as despesas financeiras, que as receitas, reduzindo momentaneamente o spread.

Embora não haja uma explicação clara sobre o comportamento do spread em relação à inflação, um impacto negativo também foi encontrado por Afanasieff et al. (2002). Ao contrário das expectativas, a constante, apesar de significante, apresentou um coeficiente negativo, o que indica existirem outras variáveis não consideradas no modelo que reduzem o spread. Contudo, o impacto da constante no spread pode ser considerado baixo $(-0,101)$.

As variáveis IHH e Market share, risco de crédito (PCD), compulsório sobre depósitos à vista (CV), Índice de Basileia (IB), taxa de crescimento do PIB e bancos estrangeiros (EXT), apresentaram sinais positivos, conforme esperado. Contudo, os resultados não foram significantes. O nível de especialização (PC), as receitas não financeiras (RNF) e os bancos públicos, também conforme esperado, obtiveram resultados com sinais negativos, mas, da mesma forma, os resultados não foram significantes.

Com base nos resultados da primeira regressão (modelo 1), realizou-se uma nova estimação com apenas as variáveis que resultaram estatisticamente significantes ao nível de $10 \%$. Os resultados são apresentados terceira coluna na Tabela 7 (regressão II).

\subsection{Estimação dos modelos da segunda etapa}

Partido dos resultados obtidos da estimação da Equação (1) e com base nos resultados da terceira coluna da Tabela 7 , propomos os dois modelos dinâmicos 
Tabela 7: Resultados das regressões da primeira etapa

\begin{tabular}{|c|c|c|}
\hline \multirow{2}{*}{$\begin{array}{c}\text { Spread } \\
\text { (Variável dependente) }\end{array}$} & Regressão I & Regressão II \\
\hline & $\begin{array}{c}\text { Coeficiente } \\
\text { (Desvio-padrão) }\end{array}$ & $\begin{array}{c}\text { Coeficiente } \\
\text { (Desvio-padrão) }\end{array}$ \\
\hline Spread $_{t-1}$ & $\begin{array}{l}0,2313248^{* * *} \\
(0,0643206)\end{array}$ & $\begin{array}{l}0,1937027^{* * *} \\
(0,0435616)\end{array}$ \\
\hline Market share (MS) & $\begin{array}{l}0,7341629 \\
(0,650797)\end{array}$ & \\
\hline $\mathrm{IHH}$ & $\begin{array}{c}0,2133769 \\
(0,2732382)\end{array}$ & \\
\hline Percentual de Crédito (PC) & $\begin{array}{l}-0,0559352 \\
(0,0769207)\end{array}$ & \\
\hline $\begin{array}{l}\text { Despesas Operacionais } \\
\text { e Administrativas (DOA) }\end{array}$ & $\begin{array}{l}1,308896^{* * *} \\
(0,1837301)\end{array}$ & $\begin{array}{l}1,158208^{* * *} \\
(0,143517)\end{array}$ \\
\hline Receitas Não Financeiras (RNF) & $\begin{array}{c}-0,267371 \\
(0,3197822)\end{array}$ & \\
\hline Imposto sobre o Resultado (IR) & $\begin{array}{l}1,169586^{* * *} \\
(0,1301303)\end{array}$ & $\begin{array}{l}1,131831^{* * *} \\
(0,1632949)\end{array}$ \\
\hline Provisões para Créditos Duvidosos (PCD) & $\begin{array}{c}0,3006669 \\
(0,2543677)\end{array}$ & \\
\hline Lucro Líquido (LL) & $\begin{array}{l}0,881466^{* * *} \\
(0,0818796)\end{array}$ & $\begin{array}{l}0,8073851^{* * *} \\
(0,0635443)\end{array}$ \\
\hline Compulsório Depósitos à vista (CV) & $\begin{array}{l}-0,0296691 \\
(0,5254246)\end{array}$ & \\
\hline Compulsório Depósitos a prazo (CPZ) & $\begin{array}{l}0,4707793^{* * *} \\
(0,0818796)\end{array}$ & $\begin{array}{l}0,3258583^{* * *} \\
(0,1131221)\end{array}$ \\
\hline Índice de Basileia (IB) & $\begin{array}{c}0,150152 \\
(0,0386983)\end{array}$ & \\
\hline Dummy Bancos Públicos (DPUB) & $\begin{array}{c}0,0386024 \\
(0,0513709)\end{array}$ & \\
\hline $\begin{array}{l}\text { Dummy Bancos com sede } \\
\text { no exterior (DEXT) }\end{array}$ & $\begin{array}{c}0,0150959 \\
(0,0218028)\end{array}$ & \\
\hline Selic (SELIC) & $\begin{array}{c}-1,094378^{* * *} \\
(0,2146214)\end{array}$ & $\begin{array}{c}-1,099419^{* * *} \\
(0,2288931)\end{array}$ \\
\hline Desemprego (DESEMP) & $\begin{array}{l}0,5524044^{* * *} \\
(0,1899592)\end{array}$ & $\begin{array}{l}0,5281288^{* *} \\
(0,2085648)\end{array}$ \\
\hline
\end{tabular}

Nota: ${ }^{* * *},{ }^{* *},{ }^{*}$, denotam significância de $1 \%, 5 \%$ e $10 \%$, respectivamente.

Todas as variáveis estão expressas em logaritmo. 
Tabela 7: Resultados das regressões da primeira etapa (continuação)

\begin{tabular}{|c|c|c|}
\hline $\begin{array}{c}\text { Spread } \\
\text { (Variável dependente) }\end{array}$ & $\begin{array}{c}\text { Regressão I } \\
\text { Coeficiente } \\
\text { (Desvio-padrão) }\end{array}$ & $\begin{array}{c}\text { Regressão II } \\
\text { Coeficiente } \\
\text { (Desvio-padrão) }\end{array}$ \\
\hline Variação do PIB (PIB) & $\begin{array}{c}0,0174947 \\
(0,0630514)\end{array}$ & \\
\hline Inflação (IPCA) & $\begin{array}{c}-0,6514258^{* * *} \\
(2314891)\end{array}$ & $\begin{array}{c}-0,537218^{* * *} \\
(0,1676081)\end{array}$ \\
\hline Constante & $\begin{array}{r}-0,1018743^{*} \\
(0,0575766)\end{array}$ & $\begin{array}{l}-0,055434^{* *} \\
(0,0232353)\end{array}$ \\
\hline Número de bancos & 73 & 73 \\
\hline Número de observacões & 2044 & 2044 \\
\hline Número de instrumentos & 81 & 81 \\
\hline Instrumentos utilizados & $\mathrm{L}(2 / 3)$ & $\mathrm{L}(2 / 3)$ \\
\hline $\operatorname{AR}(1)$ & $\begin{array}{c}z=-2,16 \\
\operatorname{Pr}>z=0,031\end{array}$ & $\begin{array}{c}\mathrm{z}=-2,08 \\
\operatorname{Pr}>\mathrm{z}=0,037\end{array}$ \\
\hline $\operatorname{AR}(2)$ & $\begin{array}{c}z=1,45 \\
\operatorname{Pr}>z=0,146\end{array}$ & $\begin{array}{c}\mathrm{z}=1,48 \\
\operatorname{Pr}>\mathrm{z}=0,139\end{array}$ \\
\hline $\begin{array}{l}\text { Hansen test overid. } \\
\text { Restrictions }\end{array}$ & $\begin{array}{l}\text { chi2 }(62)=64,20 \\
\operatorname{Pr}>\operatorname{ch} 2=0,399\end{array}$ & $\begin{array}{l}\operatorname{chi} 2(62)=72,17 \\
\operatorname{Pr}>\operatorname{ch} 2=0,472\end{array}$ \\
\hline $\begin{array}{l}\text { Hansen test } \\
\text { excluding group }\end{array}$ & $\begin{array}{l}\operatorname{chi} 2(62)=46,97 \\
\operatorname{Pr}>\operatorname{ch} 2=0,085\end{array}$ & $\begin{array}{l}\operatorname{chi} 2(62)=52,89 \\
\operatorname{Pr}>\operatorname{ch} 2=0,196\end{array}$ \\
\hline $\begin{array}{l}\text { Difference } \\
\text { (null } \mathrm{H}=\text { exogenous) }\end{array}$ & $\begin{array}{l}\operatorname{chi} 2(62)=17,23 \\
\operatorname{Pr}>\operatorname{ch} 2=0,925\end{array}$ & $\begin{array}{l}\operatorname{chi} 2(62)=19,28 \\
\operatorname{Pr}>\operatorname{ch} 2=0,860\end{array}$ \\
\hline
\end{tabular}

Nota: ${ }^{* * *}, * *, *$, denotam significância de $1 \%, 5 \%$ e $10 \%$, respectivamente.

Todas as variáveis estão expressas em logaritmo.

a seguir:

$$
\begin{aligned}
& \ln S P_{i t}=\beta_{0}+\beta_{1} \ln S P_{i t-1}+\beta_{2} \ln D O A_{i t}+\beta_{3} \ln I R_{i t}+\beta_{4} \ln L L_{i t} \\
& +\beta_{5} \ln C P Z_{i t}+\beta_{6} \ln S E L I C_{t}+\beta_{7} \ln D E S E M P_{t} \\
& +\beta_{8} \ln I P C A_{t}+\beta_{9} C N 1+\eta_{i}+\varepsilon_{i t} \\
& \ln S P_{i t}=\beta_{0}+\beta_{1} \ln S P_{i t-1}+\beta_{2} \ln D O A_{i t}+\beta_{3} \ln I R_{i t}+\beta_{4} \ln L L_{i t} \\
& +\beta_{5} \ln C P Z_{i t}+\beta_{6} \ln S E L I C_{t}+\beta_{7} \ln D E S E M P_{t} \\
& +\beta_{8} \ln I P C A_{t}+\beta_{9} C P+\eta_{i}+\varepsilon_{i t}
\end{aligned}
$$

Incorporamos nos modelos dinâmicos (4) e (5) o Capital de Nível 1 (CN1) e o Capital Principal (CP), respectivamente, que capturam os efeitos da implementação do Acordo de Basileia III. O período de análise foi modificado a fim de considerar os dados importantes para a análise dos impactos da implementação do Acordo de Basileia III, uma vez que eles começaram a ser divulgados 
pelo BCB apenas a partir do segundo trimestre de 2014. Assim, o novo período compreende desde o segundo trimestre de 2014 ao segundo trimestre de 2016.

Os resultados das estimações dos modelos (4) e (5) são apresentadas na Tabela 8. Observamos que todas as variáveis mantiveram os seus sinais e coeficientes próximos aos das regressões efetuadas na primeira etapa do estudo. Além disso, todas mostraram-se significantes, exceto o compulsório depósito a prazo e a inflação.

O spread praticado pelo banco no período anterior, as despesas operacionais e administrativas, o imposto de renda, o lucro líquido e o desemprego contribuem positivamente para a determinação do spread. Já a taxa Selic está inversamente relacionada com o spread, ou seja, a medida que a taxa de juros de referência do mercado brasileiro aumenta, o diferencial de juros entre as atividades de captação e as cobradas em empréstimos e financiamentos diminui. Nesse cenário, a inflação, os compulsórios de depósitos a prazo e a constante tiveram sinal positivo, mas foram consideradas estatisticamente não significantes para o modelo.

Mais uma vez, o teste $\mathrm{AR}(2)$ não encontrou autocorrelação entre os erros e os testes de sobreidentificação de Hansen e Difference in Hansen aprovaram os instrumentos utilizados. Nas regressões III e IV, a quantidade de instrumentos também foi truncada. Dessa vez, foram utilizadas da segunda a oitava defasagens do spread.

Interessante notar que o Capital Nível 1 apresentou sinal positivo e com significância de $10 \%$, o que confirma a suspeita de que há um efeito positivo do aumento da exigência desse tipo de capital sobre o spread. Como a equação do modelo é uma log-log linear, o coeficiente indica que caso os bancos dobrassem o seu Capital Nivel 1, o spread aumentaria em cerca de 17\%. Quando considerado o modelo com Capital Principal (Regressão IV), os resultados se mostraram muito semelhantes aos da Regressão III. O coeficiente da variável capital principal foi positivo e significante ao nível de $10 \%$, o que indica que o Acordo de Basileia III apresentou um efeito positivo sobre o spread bancário. Isso indica que a maior parte dos bancos está utilizando como Capital Nível 1 ações e instrumentos monetários que também são aceitos como Capital Principal, o que é positivo para o sistema financeiro, pois, conforme explicado na segunda seção deste artigo, o Capital Principal representa a parcela de maior qualidade e mais apta a absorver perdas.

\section{Conclusão}

Este artigo estuda os determinantes do spread bancário ex-post na economia brasileira. Em particular, desejamos ver os efeitos da implementação do acordo de Basileia III. A abordagem empírica parte do modelo teórico apresentado por Ho \& Saunders (1981) e de um modelo econométrico de painel dinâmico para 73 bancos comerciais em operação no Brasil correspondentes ao período trimestral entre 2009:2 e 2016:2.

Os resultados indicam evidências de efeitos positivos das novas exigências de Capital de Nível 1 e Capital Principal, relacionadas com a implementação do acordo de Basileia III no Brasil, no spread bancário. Nesse caso, o coeficiente estimado revela que, caso os bancos dobrassem as exigências de capital (nível 1 ou principal), gerariam uma elevação de aproximadamente $17 \%$ no 
Tabela 8: Resultados das regressões da segunda etapa - Equações (4) e (5)

\begin{tabular}{|c|c|c|}
\hline $\begin{array}{c}\text { Spread } \\
\text { (Variável dependente) }\end{array}$ & $\begin{array}{c}\text { Regressão III } \\
\text { Coeficiente } \\
\text { (Desvio-padrão) }\end{array}$ & $\begin{array}{c}\text { Regressão IV } \\
\text { Coeficiente } \\
\text { (Desvio-padrão) }\end{array}$ \\
\hline Spread $_{t-1}$ & $\begin{array}{l}0,2263228^{* *} \\
(0,0921269)\end{array}$ & $\begin{array}{l}0,2280008^{* *} \\
(0,0930118)\end{array}$ \\
\hline $\begin{array}{l}\text { Despesas Operacionais e } \\
\text { Administrativas }(\ln D O A)\end{array}$ & $\begin{array}{l}1,154976^{* * *} \\
(0,251485)\end{array}$ & $\begin{array}{l}1,155424^{* * *} \\
(0,2519558)\end{array}$ \\
\hline Imposto sobre o Resultado $(\ln I R)$ & $\begin{array}{c}0,8604243^{* * *} \\
(0,2445066)\end{array}$ & $\begin{array}{c}0,8592592^{* * *} \\
(0,2445903)\end{array}$ \\
\hline Lucro Líquido $(\ln L L)$ & $\begin{array}{c}0,7020475^{* * *} \\
(0,0708233)\end{array}$ & $\begin{array}{r}0,7029055^{* * *} \\
(0,0707071)\end{array}$ \\
\hline $\begin{array}{l}\text { Compulsório Depósitos } \\
\text { a prazo }(\ln C P Z)\end{array}$ & $\begin{array}{c}0,1983417 \\
(0,1232088)\end{array}$ & $\begin{array}{c}0,1960212 \\
(0,1232306)\end{array}$ \\
\hline Selic $(\ln S E L I C)$ & $\begin{array}{l}-4,49044^{* * *} \\
(1,672902)\end{array}$ & $\begin{array}{l}-4,4853^{* * *} \\
(1,671247)\end{array}$ \\
\hline Desemprego $(\ln D E S E M P)$ & $\begin{array}{l}0,7935536^{* * *} \\
(0,2890507)\end{array}$ & $\begin{array}{c}0,7905447^{* * *} \\
(0,2884617)\end{array}$ \\
\hline Inflação $(\ln I P C A)$ & $\begin{array}{c}0,0368864 \\
(0,2407024)\end{array}$ & $\begin{array}{c}0,0351621 \\
(0,2403687)\end{array}$ \\
\hline Capital Nível $1(\ln C N 1)$ & $\begin{array}{l}0,1729481^{*} \\
(0,0956469)\end{array}$ & \\
\hline Capital Principal $(\ln C P)$ & & $\begin{array}{l}0,1694043^{*} \\
(0,0947076)\end{array}$ \\
\hline Constante & $\begin{array}{l}-0,0127726 \\
(0,0386634) \\
\end{array}$ & $\begin{array}{c}-0,0116747 \\
(0,03841) \\
\end{array}$ \\
\hline $\begin{array}{l}\text { Número de bancos } \\
\text { Número de observações } \\
\text { Número de instrumentos } \\
\text { Instrumentos utilizados }\end{array}$ & $\begin{array}{c}73 \\
584 \\
36 \\
\mathrm{~L}(2 / 8)\end{array}$ & $\begin{array}{c}73 \\
584 \\
36 \\
\mathrm{~L}(2 / 8)\end{array}$ \\
\hline $\operatorname{AR}(1)$ & $\begin{array}{c}\mathrm{z}=-2,94 \\
\operatorname{Pr}>\mathrm{z}=0,003\end{array}$ & $\begin{array}{c}\mathrm{z}=-2,96 \\
\operatorname{Pr}>\mathrm{z}=0,003\end{array}$ \\
\hline $\operatorname{AR}(2)$ & $\begin{array}{c}z=1,37 \\
\operatorname{Pr}>z=0,170\end{array}$ & $\begin{array}{c}\mathrm{z}=1,36 \\
\operatorname{Pr}>\mathrm{z}=0,174\end{array}$ \\
\hline $\begin{array}{l}\text { Hansen test overid. } \\
\text { Restrictions }\end{array}$ & $\begin{array}{l}\text { chi2 }(62)=35,91 \\
\operatorname{Pr}>\operatorname{ch} 2=0,093\end{array}$ & $\begin{array}{l}\operatorname{chi} 2(62)=35,89 \\
\operatorname{Pr}>\operatorname{ch} 2=0,094\end{array}$ \\
\hline $\begin{array}{l}\text { Hansen test } \\
\text { excluding group }\end{array}$ & $\begin{array}{l}\operatorname{chi} 2(62)=29,70 \\
\operatorname{Pr}>\operatorname{ch} 2=0,056\end{array}$ & $\begin{array}{l}\operatorname{chi} 2(62)=29,76 \\
\operatorname{Pr}>\operatorname{ch} 2=0,055\end{array}$ \\
\hline $\begin{array}{l}\text { Difference } \\
\text { (null } \mathrm{H}=\text { exogenous) }\end{array}$ & $\begin{array}{l}\operatorname{chi} 2(62)=6,21 \\
\operatorname{Pr}>\operatorname{ch} 2=0,515\end{array}$ & $\begin{array}{l}\operatorname{chi} 2(62)=6,14 \\
\operatorname{Pr}>\operatorname{ch} 2=0,524\end{array}$ \\
\hline
\end{tabular}

Nota: ${ }^{* * *},{ }^{* *},{ }^{*}$, denotam significância de $1 \%, 5 \%$ e $10 \%$, respectivamente. 
spread bancário. Outras variáveis que foram identificadas como determinantes do spread são: despesas administrativas e operacionais, tributação, lucro líquido dos bancos e desemprego, além de uma relação estatisticamente significante e negativa com a taxa Selic.

O modelo de painel dinâmico revela que o diferencial de juros do sistema bancário nacional guarda estreita relação positiva com o valor observado no período anterior, evidenciando a importância da modelagem dinâmica. Por outro lado, a taxa Selic tem um efeito negativo no spread. Esse comportamento pode ser explicado pelo fato de a origem dos dados ser ex-post e de grande parte das operações de crédito ser prefixada, enquanto, na ponta passiva, a quase totalidade das obrigações são pós-fixadas e, em grande parte, indexadas ao CDI ou à taxa Selic. Assim, o impacto de um aumento da taxa Selic no momento " $t$ " seria sentido de forma mais rápida na taxa do passivo do banco, reduzindo, momentaneamente, o spread. A maioria dos bancos capta em taxa pós fixada (percentual do CDI) e emprestam em taxa prefixada. Quando a Selic cai, o custo da captação de recursos reduz-se imediatamente, enquanto que os empréstimos, em sua maioria prefixados, não sofrem alteração das taxas contratadas de forma que o spread aumenta. Por outro lado, quando a Selic aumenta e a taxa dos empréstimos está fixa, acontece o contrário e o spread cai.

Além disso, há um fator adicional (externo) que pode corroborar com essa relação negativa que é o poder de mercado dos bancos. Ou seja, quando a Selic cai e os preços estão fixos, os bancos não têm incentivos em repassar essa queda da Selic para os preços do crédito. Assim, eles tendem a manter os preços do crédito mais altos por mais tempo do que quando a Selic sobe e eles têm o interesse elevar mais rapidamente a taxa de empréstimo.

Os resultados encontrados neste artigo podem ser úteis para os diversos agentes da economia. Por exemplo, para o Banco Central do Brasil, regulador do sistema financeiro nacional e gestor da política monetária, o estudo traz informações úteis, quando coloca a exigência de depósitos compulsórios, o nível da taxa de juros Selic e o nível de exigência de capital como fatores que, de alguma forma, impactam o spread. O impacto dos tributos e do desemprego podem auxiliar, particularmente, o governo federal em suas decisões sobre política fiscal e trabalhista.

No que se refere aos bancos, o interesse está em todas as variáveis, pois podem argumentar junto aos demais agentes que o alto spread praticado no país é consequência da conjuntura econômica e das normas vigentes do país. Interessante notar, também, que o impacto do desemprego, proxy para o risco de crédito futuro, foi mais relevante e significante que o nível de provisão contra créditos duvidosos (PDC), proxy para o risco de crédito atual, o que indica uma maior preocupação dos bancos com a inadimplência futura em suas decisões sobre o tamanho do spread.

Além disso, para os consumidores bancários, sejam empresas ou famílias, o estudo é importante para mostrar de forma transparente os fatores mais relevantes para explicar o spread, permitindo a cobrança de ações que melhorem o seu bem-estar.

\section{Referências Bibliográficas}

Afanasieff, T. S., Lhancer, P. M. \& Nakane, M. I. (2002). The determinants of bank interest spread in Brazil. Money Affairs, Mexico City, v. 15, p. 183-207. 
Almarzoqi, R. \& Naceur, M. S. B. (2015). Determinants of Bank Interest Margins in the Caucasus and Central Asia. Washington: International Monetary Fund. Working paper. Disponível em: https://www.imf.org/external/pubs/ft/wp/2015/wp1587.pdf. Acesso em: 19 dez. 2020.

Almeida, F. D. \& Divino, J. A. (2015). Determinants of the banking spread in the Brazilian economy: the role of micro and macroeconomic factors. International Review of Economics E Finance, Amsterdam, v. 40, p. 29-39.

Angbazo, L. (1997). Commercial bank net interest margins, default risk, interest-rate risk, and off-balance sheet banking. Journal of Banking E Finance, Amsterdam, v. 21, p. 55-87.

Angelini, P., Clerc, L., Cúrdia, V., Gambacorta, L., Gerali, A., Locarno, A., Motto, R., Roeger, W., Van Heuvel, S. \& Vlcek, J. (2011). BASEL III: Longterm impact on economic performance and fluctuations. Basel: BIS. (Working Papers n. 338).

Arellano, M. \& Bond, S. (1991). Some tests of specification for panel data: Monte Carlo evidence and an application to employment equations. The Review of Economic Studies, Oxford, v. 58, p. 277-297.

Arellano, M. \& Bover, O. (1995). Another look at the instrumental variable estimation of error-components models. Journal of Econometrics, Amsterdam, v. 68, p. $29-51$.

Aronovich, S. (1994). Uma nota sobre os efeitos da inflação e do nível de atividade sobre o spread bancário. Revista Brasileira de Economia, Rio de Janeiro, p. 125-140.

Assaf Neto, A. (2004). A dimensão real do spread bancário. Federação Brasileira de Bancos. Resumo FIPECAFI, São Paulo. Disponível em: http://www. febraban. org. br/Artigos \& Análises, Estudos, textos e ensaios. Acesso em 14 fev. 2017.

BCB - Banco Central do Brasil (2013). Resolução n. 4.192, de março de 2013.

Bichsel, R., Lambertini, L., Mukherjee, A. \& Wunderli, D. C. (2019). The pass-through of bank capital requirements to corporate lending spreads. Rochester: SSRN. (SSRN 3395170). Disponível em: SSRN: https://ssrn.com/abstract=3395170. Acesso em: 19 dez. 2020.

Bignotto, F. G. \& Rodrigues, E. A. S. (2005). Fatores de risco e o spread bancário no Brasil. Brasília: Banco Central do Brasil. (Working paper n. 110).

Blundell, R. \& Bond, S. (1998). Initial conditions and moment restrictions in dynamic panel data models. Journal of Econometrics, Amsterdam, v. 87, p. 115-143.

Brock, P. L. \& Suarez, L. (2000). Understanding the behavior of bank spreads in Latin America. Journal of Development Economics, Amsterdam, v. 63, p. 113-134. 
Caggiano, G. \& Calice, P. (2011). The Macroeconomic Impact of Higher Capital Ratios on African Economies. Abidjan: African Development Bank. (Working Papers Series n. 139).

Chun, S. E., Kim, H. \& Ko, W. (2012). The impact of strengthened Basel III banking regulation on lending spreads: comparisons across countries and business models. Seoul: Bank of Korea. (Bank of Korea Working Paper n.15).

Dantas, J. A., Medeiros, O. R. \& Capelleto, L. R. (2011). Determinantes do Spread Bancário Ex-Post no Mercado Brasileiro. Brasília: Banco Central do Brasil. (Working paper n. 242).

Goldfajn, I. (2017). Painel - Projeto Spread Bancário. Brasília: Banco Central do Brasil. Disponível em: http://www.bcb.gov.br/pec/appron/apres/Apresentacao_Ilan_Goldfajn _Painel_Projeto_Spread

Guimarães, P. (2002). How does foreign entry affect the domestic banking market? The Brazilian case. Latin American Business Review, Rio de Janeiro, v. 3, p. 121-140.

Ho, T. S. \& Saunders, A. (1981). The determinants of bank interest margins: theory and empirical evidence. Journal of Financial and Quantitative Analysis, Cambridge, v. 16, p. 581-600.

Koyama, S. M. \& Nakane, M. I. (2002a). O spread bancário segundo fatores de persistência e conjuntura. Brasília: Banco Central do Brasil. (Notas técnicas do Banco Central do Brasil n. 18).

Koyama, S. M. \& Nakane, M. I. (2002b). Os determinantes do spread bancário no Brasil. Brasília: Banco Central do Brasil. (Notas técnicas do Banco Central do Brasil n. 19).

Manhiça, F. A. \& Jorge, C. T. (2012). O nivel da taxa básica de juros e o spread bancário no Brasil: uma análise de dados em painel. Brasília: IPEA. (Texto de Discussão do IPEA n. 1710). Disponível em: www.ipea.gov.br. Acesso em: 17 fev 2017.

Maudos, J. \& Guevara, J. F. (2004). Factors explaining the interest margin in the banking sectors of the European Union. Journal of Banking $\mathcal{E}$ Finance, Amsterdam, v. 28, p. 2259-2281.

Oreiro, J. L. C., Paula, L. F., Silva, G. J. C. \& Ono, F. H. (2006). Determinantes macroeconômicos do spread bancário no Brasil: teoria e evidência recente. Revista de Economia Aplicada, Ribeirão Preto, v. 10, p. 609-634.

Pinheiro, F. A. P. \& Savoia, J. R. F. (2014). Basileia III e seus impactos para os bancos no Brasil. In: XXXVIII Encontro da ANPAD. Rio de Janeiro: ANPAD. Disponível em: http://www.anpad.org.br/diversos/down_zips/73/2014_EnANPAD_FIN3 12.pdf. Acesso em: $22 \mathrm{dez} .2020$.

Saunders, A. \& Schumacher, L. (2000). The determinants of bank interest rate margins: an international study. Journal of International Money and Finance, Amsterdam, v. 19, p. 813-832. 
Silva, T. G., Ribeiro, E. P. \& Modenesi, A. M. (2016). Determinantes macroeconômicos e o papel das expectativas: uma análise do spread bancário no Brasil (2003-2011). Estudos Econômicos, São Paulo, v. 46, p. 643-673.

Valverde, S. C. \& Fernández, F. R. (2007). The determinants of bank margins in European banking. Journal of Banking E Finance, Amsterdam, v. 31, p. 2043-2063.

Windmeijer, F. (2005). A finite sample correction for the variance of linear efficient two-step GMM estimators. Journal of Econometrics, Amsterdam, v. 126 , p. 25-51.

\section{Apêndice A}


Tabela A.1: Relação de bancos da amostra

\begin{tabular}{c|l}
\hline $\mathbf{N}^{\mathbf{0}}$ & Nome do banco \\
\hline 1 & ABC-BRASIL \\
2 & ALFA \\
3 & ARBI \\
4 & BANCAP \\
5 & BANCNACION \\
6 & BANCO TOPÁZIO \\
7 & BANCOOB \\
8 & BANESE \\
9 & BANESTES \\
10 & BANIF \\
11 & BANPARA \\
12 & BANRISUL \\
13 & BASA \\
14 & BASEMSA \\
15 & BB \\
16 & BBM \\
17 & BCGB \\
18 & BCOMURUGUAI \\
19 & BIC \\
20 & BMG \\
21 & BNB \\
22 & BNO PARIBAS \\
23 & BONSUCESSO \\
24 & BPN BRASIL \\
25 & BRADESCO \\
26 & BRB \\
27 & BTMUB \\
28 & CARGILL \\
29 & CEDULA \\
30 & CEF \\
31 & CITIBANK \\
32 & CREDIT AGRICOLE \\
33 & CREDIT SUISSE \\
34 & DAYCOVAL \\
35 & DBB BM \\
36 & DEUTSCHE \\
37 & FATOR \\
38 & FICSA \\
39 & GUANABARA \\
40 & HSBC \\
41 & INDUSTRIAL DO BRASIL \\
42 & INDUSVAL \\
43 & ING \\
44 & INTERMEDIUM \\
45 & ITAÚ \\
46 & J.MALUCELLI \\
47 & JOHN DEERE \\
\hline &
\end{tabular}


Tabela A.1: Relação de bancos da amostra (continuação)

\begin{tabular}{l|l}
\hline $\mathbf{N}^{\mathbf{0}}$ & Nome do banco \\
\hline 48 & JP MORGAN CHASE \\
49 & KDB BRASIL \\
50 & KEB \\
51 & LA PROVINCIA \\
52 & LA REPUBLICA \\
53 & LUSO BRASILEIRO \\
54 & MÁXIMA \\
55 & MERCANTIL DO BRASIL \\
56 & MODAL \\
57 & PANAMERICANO \\
58 & PINE \\
59 & POTTENCIAL \\
60 & RABOBANK \\
61 & RENDIMENO \\
62 & RENNER \\
63 & RIBEIRÃO PRETO \\
64 & SAFRA \\
65 & SANTANDER \\
66 & SMBC \\
67 & SOCIETÉ GENERALE \\
68 & SOCOPA \\
69 & SOFISA \\
70 & TRIANGULO \\
71 & BTG PACTUAL \\
72 & VOTORANTIM \\
73 & WESTLB \\
\hline &
\end{tabular}


